\title{
Global Warming and Its Economic Effects on the Anchovy Fishery and Tourism Sector in North-Western Spain
}

\author{
M. Dolores Garza-Gil, M. Xosé Vázquez-Rodríguez, \\ Albino Prada-Blanco and Manuel Varela-Lafuente \\ University of Vigo \\ Spain
}

\section{Introduction}

In recent years much evidence has been gathered on climate change and its impact on different sectors and systems. Global warming is one of the main threats to sustainable development and, consequently, one of the most significant environmental challenges in the last decades affecting the economy, health and social welfare. It is necessary, therefore, to identify evidence of the impact of global warming on biodiversity and carry out an economic evaluation. In the specific case of marine ecosystems, changes in rainfall frequency and intensity, acidity, water temperature, wind, dissolved $\mathrm{CO}_{2}$ and salinity, combined with anthropogenic nutrient and toxin contamination, can affect water quality both in coastal regions as well as in the open sea. All of this will consequently affect the productivity of the marine environment. And given that fishing is one of the economic activities which critically depend on natural conditions or characteristics, the influence of environmental changes on fishing is notably higher than that which might occur in other primary activities. Furthermore, climate has a vital impact on the tourism and recreation sector and, therefore, this sector will be affected by any changes in climate.

In this chapter, we assess the possible economic effects (losses or gains) of global warming on some of the main economic activities in north-western Spain. The economy of this region specialises in products derived from fishing and aquaculture as well as tourism, among others (IGE - Galician Statistics Institute-, 2010), and both activities are extremely sensitive to environmental conditions. It is highly probable that global warming will alter the intensity and conformation of ocean currents, affect marine organisms and generate coastal alterations (IPCC, 2007). Such environmental changes will have important repercussions on these economic activities.

A considerable number of studies have been carried out internationally which have aimed to assess the economic effects of climate change on these activities. Among other references in the case of fishing, we would underline the following: Arnason (2005) evaluates the possible impact of climate change on Iceland's fishery production, proposing different scenarios involving temperature increase; along the same lines, Eide (2005) analyses the possible impact on the Barents Sea fisheries; Gallagher (2005) makes an application to the New Zealand cod fishery, differentiating between zone and fishing method; Röckmann 
(2005) analyses the effects of possible changes in salinity on the Baltic cod fishery; Sissener \& Bjorndal (2005) study the effect of climate change on the migratory patterns of the Norwegian herring; Arnason (2006) proposes a theoretical model into which he introduces the risks deriving from global warming; Briones et al (2006) develops a model applied to small pelagic species in fisheries in India, the Philippines and Thailand; Hannesson (2006) analyses the effects of warming on the Norwegian herring fishery; Herrick et al (2006) make an application to the sardine fishery in north-American Pacific waters; and Garza-Gil et al (2011) evaluate the effects on the Ibero-atlantic sardine fishery.

In relation with the references which study the complex relationship between climate change and tourism, most of them point out that not only will the volume of tourism flows change but the destinations as well (Smith, 1990, 1993); Viner \& Agner, 1999; Maddison, 2001; Lise \& Tol, 2002; Scott et al., 2004, 2005; Hamilton et al., 2005a, 2005b; Gómez Martín, 2005; Bigano et al., 2006, among others. In Europe, we would underline the PESETA study (European Commission, 2007) to evaluate the impacts forecast in Europe for the time periods 2011-2040 and 2071-2100, and which predicts that summer climate conditions will change radically and that the zone that currently has excellent conditions (the Mediterranean) will be displaced northwards (figure 1). In the case of Spain, the Spanish Climate Change Office reaches similar conclusions, predicting a "Mediterraneanisation" of the north of the peninsula and the aridization of the south (Ministry of the Environment, 2005). This result is particularly relevant for the research carried out, as we will see that for Galicia tourism flows come directly from the rest of Spain and this Mediterraneanisation of the north might generate a change in direction to the north from the current flows to the south. In this respect, the analysis by Bigano et al. (2004), which points out that approximately $86 \%$ of total tourism is the domestic or internal tourism of each country, is confirmed when we analyse the tourism flows from the rest of Spain to the north-west of the country. It should also be pointed out that, given the volume of domestic tourism, the analysis of the effects of climate change has in general dealt with international tourism, obviating internal or domestic tourism (Seddighi \& Shearing, 1997; Coenen \& Van Eekeren, 2003).

For this chapter and in relation with fishing activity, the study case chosen is the anchovy (Engraulis encrasicholus) fishery, it being a hugely important pelagic species for the fisheries sector in the region analysed. The pelagic species would be among those most affected by the impacts of climate change on seas and oceans due to the high level of instability and sensitivity to environmental impacts. These species are especially sensitive to temperature changes and the upwelling of nutrients in the marine environment. Therefore, any water temperature variation will have repercussions to a greater or lesser extent on these species' reproduction levels. In particular, we assess the possible economic effects of global warming on this fishery and sea surface temperature management is introduced into the management problem. This variable allows us to gather evidence of climate change and its repercussion on ecosystems and marine species, which are the bases of fish reproduction functions (McGowan et al., 1998; Levitus et al., 2000; IPCC, 2001; Stenevik and Sundby, 2007). Other variables, such as the frequency and intensity of rainfall, acidity, dissolved carbon and salinity, are also prone to experience environmental changes; however there is a high level of correlation between all of these variables. In this study, we describe the evolution of fish biomass, based on the sensitivity of the species' growth function with respect to fluctuations in oceanographic conditions (through the sea temperature), and will analyse impacts on the economic yield of the fishery deriving from a possible change in the temperature conditions 

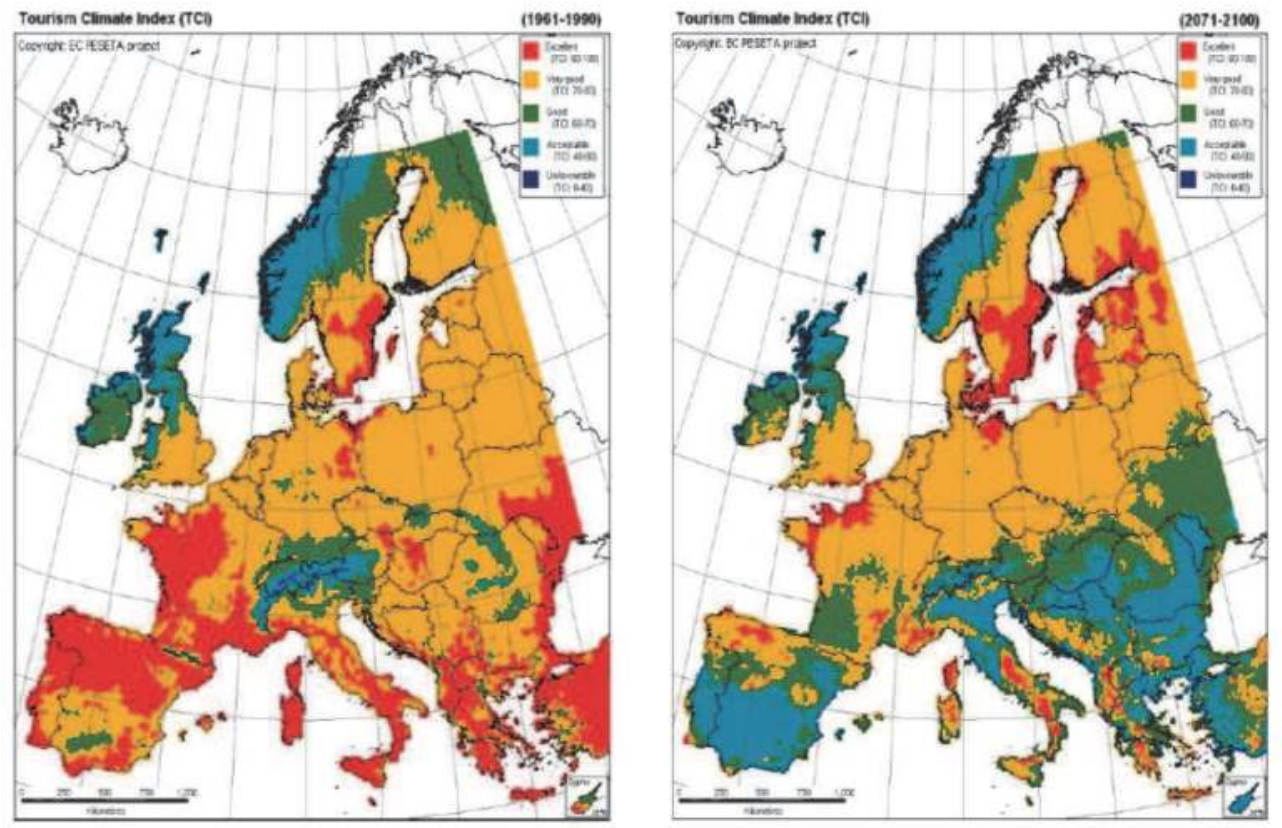

Source: PESETA Project (www.jrc.es/docs/Tourism.html) cited in EEA (2007).

Fig. 1. Simulations for summer tourism en Europa for 1961-1990 (left) and 2071-2100 (right), based on high emissions scenario of IPCC A2.

of the marine ecosystem. We will apply a bio-economic model for evaluating these effects on the fishing profits.

With relation to tourist activity, the physical changes in the coastal landscape, in the availability of certain resources or basic provisions (water, energy, food, etc.), in risks to health (new illnesses, effects of extreme temperatures) and the risk of catastrophic events (droughts, floods, storms and extreme weather conditions) are some of the consequences of climate change that will directly influence tourism. We assess the possible effects of global warming on tourist visits to the north-west of Spain. The analysis is based on prior qualitative information gathered on expected changes in the climate at different times of the year in Spain, the main source of tourist demand in the region studied. A prior description or zero scenario of tourism flows to the region is carried out. On this basis, changes in tourist preferences to estimate how the new climate scenario will affect tourist travel to the region are analysed. The methodology used consists of a field study based on direct methods using questionnaires presented to a representative sample at the source market. The objective market chosen was Madrid, the main tourist source market for the north-west of Spain. Climate is hugely important in the satisfaction or dissatisfaction of tourist visits at present and, in consequence, the choice of destination.

The structure of the chapter is as follows: in section 2, we will analyse the effects of climate change on the anchovy fishery, while section 3 deals with effects on tourist activity. Lastly, in section 4, we will sum up the study's main conclusions. 


\section{Effects of climate change on the anchovy fishery}

Given that fishing activity is one of the economic activities which most critically depends on natural conditions or characteristics, the influence of environmental changes on fishing is notably higher than that which might occur in other primary activities (Hannesson 2006). It is assumed with some degree of probability that global warming will alter the intensity and disposition of ocean currents, and the effect of this, among others, will mean an increase in ocean temperatures, variations in salinity levels and changes in upwellings (ACIA 2004; IPCC 2007). The impacts will differ according to ecosystems and coastal or ocean zones, and will affect different groups of organisms, from phytoplankton and zooplankton to fish and algae (Ministry of the Environment 2006). Among these organisms, pelagic species (and, in particular, small pelagic species), on account of their high level of instability and sensitivity to environmental impacts, will be among those most affected by the impacts of climate change on seas and oceans. The small pelagic species are target species for the majority of the Spanish fleet, in general, and for the north-west in particular; and, of these, the anchovy is important on account of its high commercial value. For this reason, any significant modification in anchovy biomass levels can affect fishermen's net profits. We will begin by describing the situation of this fishery.

\subsection{The situation of the fishery}

The Spanish purse seine fishery in the Atlantic is made up of 491 vessels, of which 346 fish in north-western Cantabrian waters and the remaining 146 in the waters of the Canary Islands and the Bay of Cadiz (MAPA, 2008). It is one of the fleets with the most vessels operating in these waters, second only to the artisanal fleet, and it targets small pelagic species, among which are the sardine, horse mackerel, mackerel and the anchovy (MAPA, 2008; Ibermix, 2007). The Spanish purse seine fleet in the North Atlantic is made up of relatively homogenous vessels insofar as their technical characteristics are concerned, with an average capacity of $34.2 \mathrm{GT}$, power of $151.8 \mathrm{Kw}$ per vessel and a length of $21 \mathrm{~m}$. The average life of the fleet is 20 years, with a crew of 8 per vessel. All of the vessels use nets made from synthetic materials, they are equipped with hydraulic haulers and electronic fish detectors.

Regarding the management, in general there are no specific regulations from the European Union. Given the poor situation in which the anchovy has found itself over the last years, a precautionary TAC was implemented for several years and a moratorium for this species has been in place in the Bay of Biscay since 2005. The Spanish government uses input control (area restrictions, entrance restrictions and gear regulation) and, in addition, some regional governments implement output control for some species (maximum catches per fishing day in the case of the anchovy).

This fleet targets pelagic species, in this case, the sardine and the anchovy. The anchovy has been subject to a precautionary TAC in area VIIIc for several years, but since the collapse of this species in 2005, the European Union established a moratorium (ICES, 2008). Stock biomass has been low because recruitment has been low since 2002, and the fishery has been closed since 2005. There are no indications how long the low recruitment will last and whether a continued low SSB will reduce future recruitments. Biologists consider it likely that the closure of the fishery over the last few years has led to an increase in the abundance of older anchovy, and because of the very low recruitment in 2008, the contribution of older fish to spawning in 2009 will be crucial. The fishery was opened again in 2010 and the EC 
implemented a TAC of 7,000 tons. In any case, the harvest control rules for anchovy are currently under development. Under the rules being considered, a TAC is set on the basis of the estimated spawning biomass and may be set for the whole period July-June, with or without a provision to revise it at the beginning of the year based on the results of juvenile surveys. The criterion for accepting these rules as precautionary would be that the rule implies a low risk of reducing the SSB to a level which may imply further reduction in recruitment (ICES, 2008). Other supplementary measures (area closures, minimum landing size) may be considered in addition to TACs.

\begin{tabular}{|c|c|c|c|}
\hline Year & $\begin{array}{c}\text { Sea Surface } \\
\text { Temperature } \\
\left({ }^{\circ} \mathbf{C}\right)\end{array}$ & $\begin{array}{c}\text { Anchovy } \\
\text { Biomass } \\
\text { (tons) }\end{array}$ & $\begin{array}{c}\text { Catches in } \\
\text { Spain } \\
\text { (tons) }\end{array}$ \\
\hline 1987 & 16.08 & 34128 & 15308 \\
\hline 1988 & 16.13 & 51754 & 20302 \\
\hline 1989 & 16.62 & 30193 & 16558 \\
\hline 1990 & 16.61 & 81330 & 40759 \\
\hline 1991 & 15.86 & 43675 & 25556 \\
\hline 1992 & 16.02 & 18286 & 41051 \\
\hline 1993 & 15.88 & 117981 & 42377 \\
\hline 1994 & 16.08 & 79257 & 38019 \\
\hline 1995 & 16.45 & 97017 & 43071 \\
\hline 1996 & 16.32 & 78517 & 38968 \\
\hline 1997 & 16.76 & 71573 & 27632 \\
\hline 1998 & 16.64 & 124322 & 42579 \\
\hline 1999 & 16.50 & 102308 & 34668 \\
\hline 2000 & 16.41 & 132228 & 39496 \\
\hline 2001 & 16.48 & 113063 & 49247 \\
\hline 2002 & 16.24 & 46391 & 26313 \\
\hline 2003 & 16.62 & 41317 & 15864 \\
\hline 2004 & 16.36 & 52016 & 22205 \\
\hline 2005 & 16.49 & 24413 & 5643 \\
\hline 2006 & 16.51 & 37141 & 6244 \\
\hline 2007 & 16.54 & 49579 & 6595 \\
\hline 2008 & 16.56 & 36532 & 6457 \\
\hline
\end{tabular}

Source: Own compilation from ICES (2008) and, for the temperature, Spanish Centre for Higher Scientific Research.

Table 1. The fishery.

The landings of this species were on the increase up to the year 2000, after which they dropped until the temporary closure of the fishery was imposed on account of poor stock recruitment in preceding years (table 1). For application purposes, we will not bear in mind the data corresponding to the period 2005-2008 due to the moratorium established by the European Commission for this stock, given that it is not the usual situation in the fishery. In figure 2, we can observe the variability that exists in the evolution of the biomass. However, in general, and except in the middle years of the period, as the sea surface temperature in this zone increased, the biomass dropped in the same way as catches, especially in the last 
years of the period analysed. And in table 2 we can observe the correlation matrix between these three variables, from which it can be gathered that variations in the sea temperature generate variations of the opposite kind in biomass and catches.

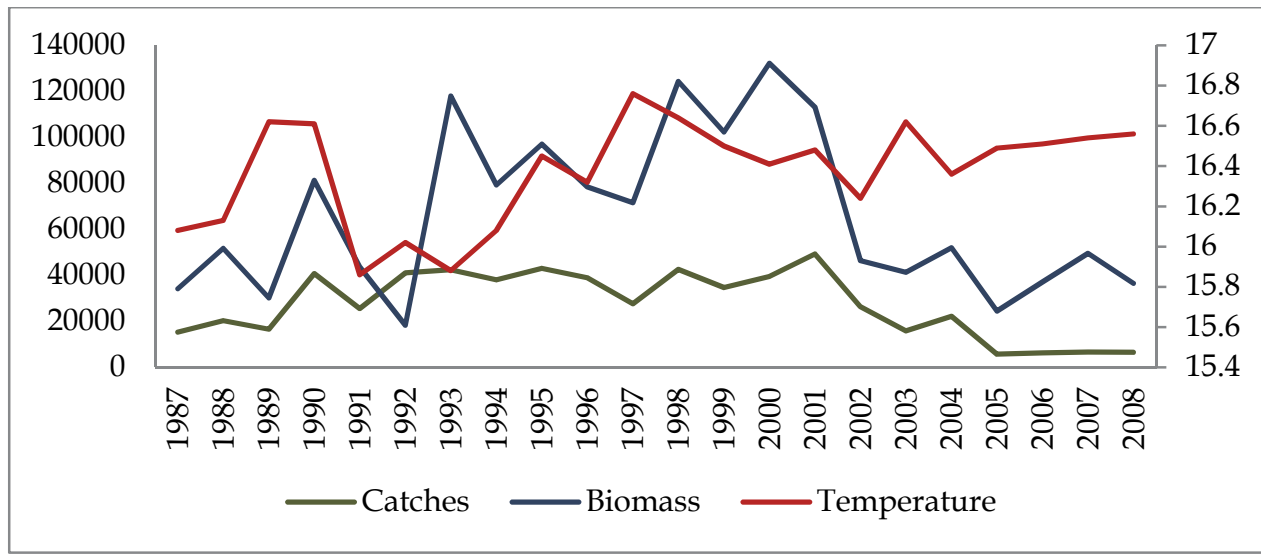

Fig. 2. Evolution of fishery. 1987-2008.

With regard to the economic parameters, we have average data for the period 1995-2006 from the European Commission (2006) and from direct interviews with fishery sector representatives. On this basis, the price per unit of catches landed $(p)$ stands at $3950.01 € /$ ton (constant euros for 2008); the cost per unit of catch (c) stands at $982.7 € /$ ton (constant euros for 2008); and the discount rate $(\delta)$ is approximately $5 \%$.

\begin{tabular}{|c|c|c|c|c|}
\hline & Biomass & $\begin{array}{c}\text { Biomass } \\
\mathbf{t + 1}\end{array}$ & Catches & Temperature \\
\hline Biomass & 1.0000 & & & \\
\hline Biomass $\mathrm{t}+1$ & 0.7923 & 1.0000 & & \\
\hline Catches & 0.7141 & 0.7428 & 1.0000 & \\
\hline Temperature & -0.4659 & -0.6366 & -0.6781 & 1.0000 \\
\hline
\end{tabular}

Table 2. Correlation matrix among the variables biomass, catch and temperature

On the other hand, the north-west zone represents $36 \%$ of the total fishery insofar as anchovy landings for the period 1995-2006 are concerned. This will be the data we will use as a reference to estimate the variations in net profits in the face of the new climate scenario.

\subsection{Methodology}

Bio-economic modeling enables us to incorporate natural, environmental and institutional contributing factors, as well as typically economic factors, into a single analytical body. For the specific case of fisheries, the aim is to control the size of the fish population by limiting catches (or fishing effort) in such a way as to maximise the present value of the flow of net profits generated by the fishery over a specific time horizon and bearing in mind the dynamics of said natural resource. In this way, we can determine the extent to which society can invest (or disinvest) in the natural resource and what the appropriate extraction rate would be over time, allowing for the sustainable exploitation of said resource. 
Given that we do not have data on fishing effort for this fishery, we can represent the bioeconomic problem in simplified form as follows:

$$
\begin{aligned}
& \operatorname{Max}_{h} \int_{0}^{\infty} \pi(X, h) e^{-\delta t} d t \\
& \text { s.a. } \dot{X}=\frac{d X}{d t}=F(X)-h(t)
\end{aligned}
$$

where $\pi(X, h)=[p-c] h(t)$ represents the net profits generated by fishing in the instant $t, X$ the fish population, $h$ the catch rate, $p$ the price per unit of fish, $c$ the cost per unit of fishing, $\delta$ the social discount rate and $F$ the natural dynamics of the fish population (or the natural growth function of the stock without considering human activity). The fundamental problem (Kamien \& Swartz, 1991) consists of determining the optimal feasible control, $h(t)=h^{*}(t)$ con $t \geq 0$, which maximises the objective function while satisfying the problem's conditions in the new climate context.

In order to resolve the problem (1), we need to previously define marine resource dynamics $\dot{X}$. This function is statistically tested on the basis of the data that exists on biomass, catches and, in our case, the sea surface temperature, generally using Ordinary Least Squares. From the data in table 1, and once the correlation matrix shown in table 2 has been obtained, the function which presents the best economic results is as follows:

$$
\dot{X}=\alpha X_{t}+\beta X_{t}^{2}+\gamma T_{t}-h_{t}
$$

The equation (2) corresponds to the logistic model, widely used in fisheries economics literature, where $\alpha, \beta$ and $\gamma$ are parameters containing biological information on anchovy stock, and $T$ denotes the sea surface temperature. The concrete results of the econometric estimation of (2) are shown in table 3. Therefore, the concrete form of this function is given by the following expression:

$$
\dot{X}=1.98 X_{t}-0.7 E^{-5} X_{t}^{2}-0.03648 T_{t}-h_{t}
$$

\begin{tabular}{|c|c|}
\hline & $X_{t+1}+h_{t}=\alpha X_{t}+\beta X_{t}^{2}+\gamma T_{t}$ \\
\hline$\alpha$ & $1.98(4.86)$ \\
\hline$\beta$ & $-0.7 \mathrm{E}^{-5}(-2.28)$ \\
\hline$\gamma$ & $-0.03648(-2.14)$ \\
\hline $\mathrm{Jb}$ & 0.3564 \\
\hline $\mathrm{Q}-$ Stat & 0.0883 \\
\hline $\mathrm{LM}($ ARCH$)$ & 0.8153 \\
\hline $\mathrm{R}^{2}$ & 0.7982 \\
\hline $\mathrm{R}^{2}$ adjusted & 0.7684 \\
\hline
\end{tabular}

Note: t-ratio between brackets. Jb is the Jarque-Bera statistic of the normality test; Q-Stat is the LjungBox statistic used in the correlation test; LM (Lagrange multiplier) is the one used in the heteroscedasticity test; and AIC is the statistic used in the prediction error model.

Table 3. Econometric results for growth function of anchovy biomass. 
In this way, the Hamiltonian function in usual terms (current moment $t$ ) associated with problem (1) is given by the following expression:

$$
H(X, h, t ; \mu)=(p-c) h_{t}+\mu\left(\alpha X_{t}-\beta X_{t}^{2}-\gamma T_{t}-h_{t}\right)
$$

where $\mu$ denotes the shadow price of the marine resource in current terms.

The conditions necessary (Kamien \& Swartz, 1991) to solve the problem are given by the expressions:

$$
\begin{gathered}
\frac{d H(X, h, t ; \mu)}{d h}=0==>(p-c)-\mu=0 \\
\dot{\mu}-\delta \mu=-\frac{d H(X, h, t ; \mu)}{d X}=-\mu(\alpha-2 \beta X) \\
\frac{d X}{d t}=0==>\alpha X-\beta X^{2}-\gamma T-h=0
\end{gathered}
$$

By using expressions (5)-(7) the catch level is obtained $h^{*}(t)$, which will depend on the level of sea surface temperature, as will stock dynamics (expression (2)):

$$
h^{*}=\alpha\left(\frac{\alpha-\delta}{2 \beta}\right)-\beta\left(\frac{\alpha-\delta}{2 \beta}\right)^{2}-\gamma T
$$

Once this level is known, we can obtain the losses or profits associated with the new climate scenario in relation with the fishery's present situation through the net profit function for the fishery.

\subsection{Results}

Declines in the abundance of the most important commercial fish species have often considered as a result of overfishing and occasionally from a combination of environmental effect and fishing pressure (IPCC, 2001). The impacts of climate variations have been shown to have substantial effects on decreases as well as increases in stock abundance, and the success of the future fish stock assessment depends to a large extent on the ability to predict the impacts of climate change on the dynamics of marine ecosystems.

The temperature in the North Atlantic has shown, in general, an increasing trend over the recent three decades. It may be an indication of the climate change caused by emission of different greenhouse gases. However, there is natural variability in the climate in addition to long term climate change induced by anthropogenic activity. And the difficulty in obtain many highly confident outcomes is why the term "climate scenarios" has been adopted in most impact assessment (IPCC, 2001). The climate scenarios should be regarded as internally consistent patterns of plausible future climates, and not predictions based in probabilities. Since most climate models focus on the atmosphere, the climate change scenarios for the ocean are particularly prone to uncertainty (Stenevik \& Sundby, 2007). It is, however, concluded that the global warming will affect the ocean through changes in the sea temperature, among other variables (IPCC, 2001). And it has been shown that there has been a general warming of a large part of the world oceans during the past fifty years (Levitus et al., 2000). For the Ibero-Atlantic waters, the sea surface temperature is expected to increase by approximately the same amount as in the last decades (Rosón, 2008), this is $0.027^{\circ} \mathrm{C}$ per year ("Current warming" scenario in table 4).

In the table 4, the results obtained in the face of sea surface temperature increases in these fishing grounds are shown for different climate scenarios. For the current warming scenario, 
we can see that as the sea surface temperature increases, both the catch level as well as the net profits fall for the overall fishery. In the specific case of the net profits, the decrease is estimated to stand at $1.28 \%$ using the year 2040 as the time horizon, a medium-term time horizon established in the European Commission's Peseta Report (EEA, 2007).

\begin{tabular}{|c|c|c|c|c|c|}
\hline $\begin{array}{c}\text { Current } \\
\text { Warming }\end{array}$ & Tigher & & Warming \\
\hline $\begin{array}{c}\text { Temperature } \\
\left({ }^{\circ} \mathbf{C}\right)\end{array}$ & $\begin{array}{c}\text { Catches } \\
\text { (tons) }\end{array}$ & $\begin{array}{c}\text { Net } \\
\text { Benefits } \\
\text { (euros) }\end{array}$ & $\begin{array}{c}\text { Temperature } \\
\mathbf{(}^{\circ} \text { C) }\end{array}$ & $\begin{array}{c}\text { Catches } \\
\text { (tons) }\end{array}$ & $\begin{array}{c}\text { Net } \\
\text { Benefits } \\
\text { (euros) }\end{array}$ \\
\hline 16.6790 & 13991.89542 & 41519550.5 & 16.6979 & 13849.31678 & 41096462.6 \\
\hline 16.7060 & 13991.89444 & 41519547.6 & 16.7276 & 13849.31570 & 41096459.4 \\
\hline 16.7330 & 13991.89346 & 41519544.7 & 16.7573 & 13849.31462 & 41096456.2 \\
\hline 16.7600 & 13991.89248 & 41519541.8 & 16.7870 & 13849.31355 & 41096453.0 \\
\hline 16.7870 & 13991.89150 & 41519538.9 & 16.8167 & 13849.31247 & 41096449.8 \\
\hline 16.8140 & 13991.89053 & 41519535.9 & 16.8464 & 13849.31139 & 41096446.6 \\
\hline 16.8410 & 13991.88955 & 41519533.0 & 16.8761 & 13849.31032 & 41096443.4 \\
\hline 16.8680 & 13991.88857 & 41519530.1 & 16.9058 & 13849.30924 & 41096440.2 \\
\hline 16.8950 & 13991.88759 & 41519527.2 & 16.9355 & 13849.30816 & 41096437.0 \\
\hline 16.9220 & 13991.88661 & 41519524.3 & 16.9652 & 13849.30709 & 41096433.8 \\
\hline 16.9490 & 13991.88563 & 41519521.4 & 16.9949 & 13849.30601 & 41096430.7 \\
\hline 16.9760 & 13991.88465 & 41519518.5 & 17.0246 & 13849.30493 & 41096427.5 \\
\hline 17.0030 & 13991.88368 & 41519515.6 & 17.0543 & 13849.30386 & 41096424.3 \\
\hline 17.0300 & 13991.88270 & 41519512.7 & 17.0840 & 13849.30278 & 41096421.1 \\
\hline 17.0570 & 13991.88172 & 41519509.8 & 17.1137 & 13849.30170 & 41096417.9 \\
\hline 17.0840 & 13991.88074 & 41519506.9 & 17.1434 & 13849.30063 & 41096414.7 \\
\hline 17.1110 & 13991.87976 & 41519504.0 & 17.1731 & 13849.29955 & 41096411.5 \\
\hline 17.1380 & 13991.87878 & 41519501.1 & 17.2028 & 13849.29847 & 41096408.3 \\
\hline 17.1650 & 13991.87780 & 41519498.2 & 17.2325 & 13849.29740 & 41096405.1 \\
\hline 17.1920 & 13991.87682 & 41519495,3 & 17.2622 & 13849.29632 & 41096401.9 \\
\hline 17.2190 & 13991.87585 & 41519492.4 & 17.2919 & 13849.29524 & 41096398.7 \\
\hline 17.2460 & 13991.87487 & 41519489.5 & 17.3216 & 13849.29417 & 41096395.5 \\
\hline 17.2730 & 13991.87389 & 41519486.6 & 17.3513 & 13849.29309 & 41096392.3 \\
\hline 17.3000 & 13991.87291 & 41519483.7 & 17.3810 & 13849.29201 & 41096389.1 \\
\hline 17.3270 & 13991.87193 & 41519480.8 & 17.4107 & 13849.29094 & 41096385.9 \\
\hline 17.3540 & 13991.87095 & 41519477.9 & 17.4404 & 13849.28986 & 41096382.7 \\
\hline 17.3810 & 13991.86997 & 41519475.0 & 17.4701 & 13849.28878 & 41096379.5 \\
\hline 17.4080 & 13991.86899 & 41519472.1 & 17.4998 & 13849.28771 & 41096376.3 \\
\hline
\end{tabular}

Table 4. Results of estimations.

Table 4, on the other hand, also shows the results for these variables when faced with an even greater increase in sea surface temperature in these fishing grounds. As was foreseeable, there is an even sharper decrease in both variables. It should be noted that in any of the thermal oscillation scenarios, the level of catches obtained is lower than the average for the period 1987-2008. 


\section{Effects of climate change on tourism}

Given that the aim is to carry out a preliminary estimation of changes in tourism flows to the north-west coast from one of the visitors' main source markets at present, it is necessary to begin by clarifying the basic terminology and, consequently, by delimiting the work done. In this sense, the World Tourism Organisation establishes that if an activity is to be considered a tourist activity, it must involve at least one overnight stay away from the permanent residence. Thus, for example, Evans et al. (2000) differentiate between these activities which involve overnight stays and a certain prior planning of recreational activities away from home in general which would be included in the concept of recreation or recreational activities. In the study described below, we will look exclusively at tourism flows according to the internationally-accepted definition, which does not cover recreational activities. This differentiation is also significant for the study's aims, as tourist trips are usually strongly conditioned by climate (when choosing destination and date), while recreation depends more on short-term weather forecasts. In this respect, Limb \& Spellman (2001) identify the climatic factors that most influence tourists' decisions and observe that they are temperature, sun and rain. We will take into consideration the direct effect of climate change on tourism demand, and not look at indirect effects (through changes to the landscape, natural resources, etc.). Firstly, we need to identify the tourism destinations and uses of Madrid residents at present and the variables which affect their choice of destination. Secondly, we will reveal how preferences are modified under a climate change scenario, initially in their own region, but then also in different coastal destinations currently preferential for Madrid residents (especially the Mediterranean and the northwest). We will begin by presenting a description of current tourism demand in Galicia. Then we will briefly describe the methodology used to estimate changes in future demand and present the main results obtained.

\subsection{Analysis of tourism demand under the baseline scenario}

From the data presented in table 5, the relative decisive importance of domestic tourism in comparison with foreign tourism can be observed when we analyse tourist visits to the north-west of Spain (Galicia) 2008. This would explain why a single domestic market (Madrid) makes up half of the total figure for tourism from outside Spain to Galicia. This is also true in terms of the value of increased consumption, although the source used would seem to overestimate the former and underestimate the tourism that comes from the rest of Spain (36\% of overnight stays generates only $18 \%$ of consumption). This said, it should be underlined that the estimation of tourism consumption received from the rest of Spain (in which Madrid is fundamental) is very similar to the importance of foreign tourism consumption (907 and 1187 million, respectively).

Of the 46 million overnight stays ${ }^{1}$ by domestic tourists, 18.3 million (40\%) are explicitly identified as summer holidays. To these we should add, among others, visits to family and friends, which can also be highly seasonalised. Per type of accommodation, the distribution of these overnight stays in visitors' own homes and/or those belonging to family and friends (which exceed $53 \%$ of the total) will be closely related to the data on access to a second home. It is significant that with regard to Galicia, in $85 \%$ of cases the location of this

1 The number of overnight stays in hotel accommodation is an "...indicator that in terms of volume it is much more significant than the mere arrival of tourists" (Xunta de Galicia 2005: 13). 


\begin{tabular}{|c|c|c|c|c|}
\hline & $\begin{array}{c}\text { Overnight } \\
\text { stays (people) }\end{array}$ & $\%$ & $\begin{array}{c}\text { Consumption } \\
\text { (millions of } \\
\text { euros) }\end{array}$ & $\%$ \\
\hline Domestic total & $46,166,152$ & 79.5 & 3,929 & 76.8 \\
\hline - Residents & $24,889,152$ & 42.7 & 3,022 & 59.1 \\
\hline - Rest of Spain & $21,277,140$ & 36.5 & 907 & 17.7 \\
\hline Madrid $^{1}$ & $6,497,107$ & 11.2 & n.a & n.a \\
\hline Rest $^{2}$ & $14,730,033$ & 25.3 & n.a & n.a \\
\hline $\begin{array}{c}\text { From outside } \\
\text { Spain }\end{array}$ & $11,922,500$ & 20.5 & 1,187 & 23.2 \\
\hline Total & $58,088,652$ & 100.0 & 5,187 & 100.0 \\
\hline
\end{tabular}

${ }^{1}$ Makes up $5 \%$ of overnight stays, where the feeder market is Madrid, in the rest of Spain.

${ }^{2}$ Cataluña comes after Madrid, with 3,190,147 visits. Source: www.iet.tourspain.es e www.exceltur.org

Table 5. Analysis of visits and visitors.

second home is in Galicia, whereas with regard to Madrid in $84 \%$ of cases the second home is situated outside the region, that is, completely the opposite.

Non-regulated establishments are defined as homes and apartments not legalised as lodgings for business purposes, and therefore reliable statistics in this regard do not exist. For this reason, in order to assess their importance within the tourism sector, we need to resort to indicators that relate to their effective use, such as the overnight stays in nonregulated accommodation by Spanish and foreign tourists. However, we do not have disaggregated data at local level, which obliges us to make ad hoc estimations. The data for the three Galician provinces with a coastline is as shown in the Table 6.

\begin{tabular}{|c|c|c|c|c|c|}
\hline NW coastal provinces & Regulated & Non-regulated & Total & $\begin{array}{c}\text { \% Non- } \\
\text { regulated }\end{array}$ & $\begin{array}{c}\text { \% } \\
\text { prov./GAL }\end{array}$ \\
\hline A Coruña & $3,857,573$ & $11,267,254$ & $15,124,827$ & $74.5 \%$ & $27.8 \%$ \\
\hline Lugo & 925,826 & $10,032,247$ & $10,958,072$ & $91.5 \%$ & $20.1 \%$ \\
\hline Pontevedra & $3,798,427$ & $12,425,654$ & $16,224,081$ & $76.5 \%$ & $29.8 \%$ \\
\hline Galicia (GAL) & $9,191,098$ & $45,099,554$ & $54,290,652$ & $83.0 \%$ & $3.4 \%$ \\
\hline Spain & $344,022,030$ & $1,228,798,432$ & $1,572,820,462$ & $78.1 \%$ & \\
\hline
\end{tabular}

Source: Compiled by the authors based on data from Anuario económico de La Caixa.

Table 6. Regulated and non-regulated overnight stays in the Galician coastal provinces.

As we can see in the table, overnight stays in non-regulated establishments account for more than three-quarters of the total in Galicia. Such a volume of non-regulated tourism business stands at a slightly higher rate than the average for Spain (5\% more), making it especially appropriate to evaluate the real behaviour (under the baseline scenario) or potential behaviour (under a climate change scenario) from the point of view of tourism demand (in our case, the source market of Madrid), as to do so from the point of view of regulated supply ${ }^{2}$ would involve only looking at a minor part of tourism uses associated with the use of the coast. On the other hand, overnight stays in coastal areas are especially decisive for

${ }^{2}$ By its very nature, it would be difficult for non-regulated supply to be the subject of a statistical analysis in fieldwork that could be considered rigorous. 
the region as a whole, as the main reason for approximately $44 \%$ of domestic trips is to visit and enjoy its beaches (Familitur, 2006).

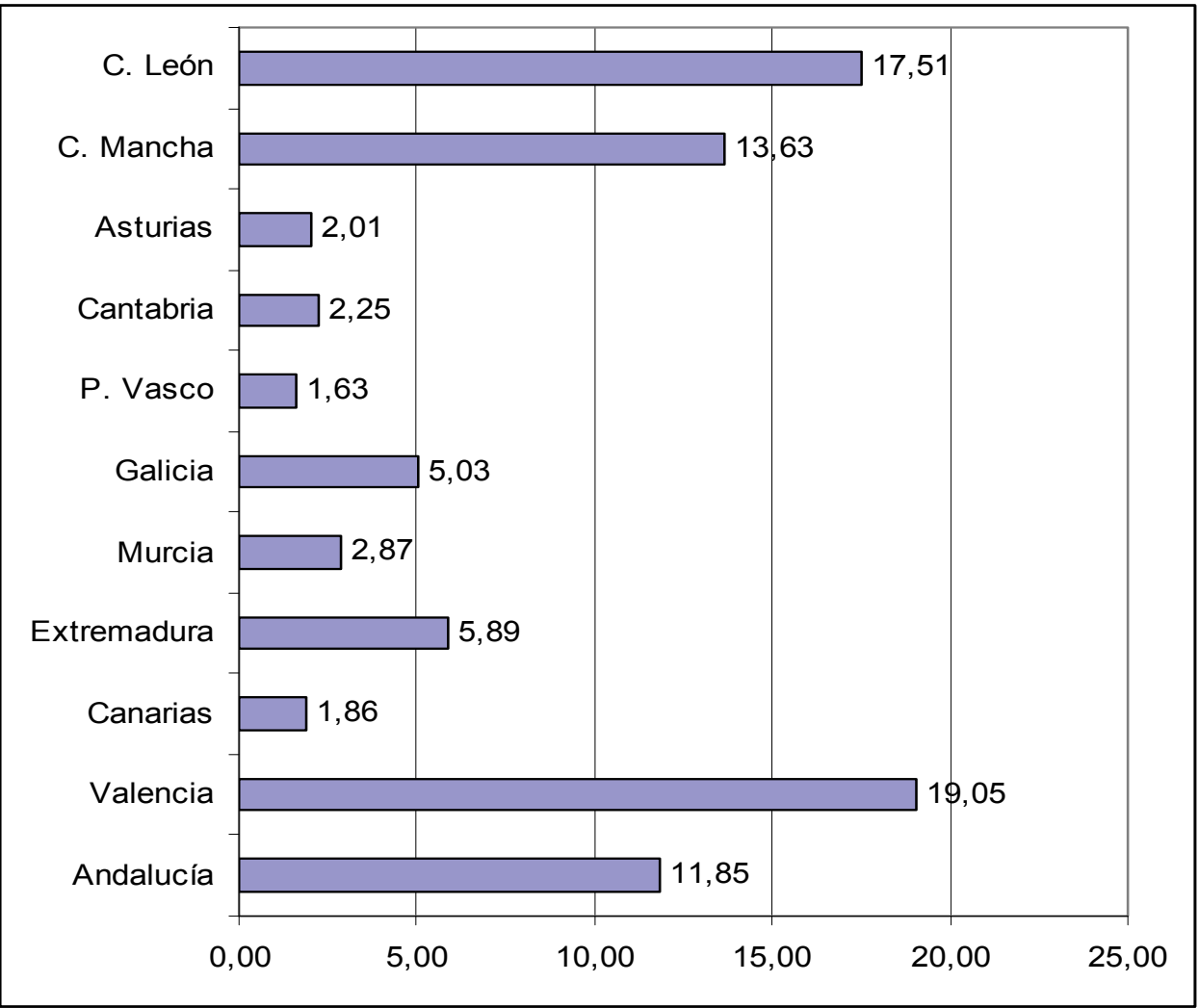

Source: Compiled by the authors based on data from Familitur, 2006.

Fig. 3. Distribution of tourism destinations visited by Madrid residents. Overnight stays with domestic destinations in Spain.

With regard to domestic tourism, the case of Madrid is notable. Therefore, as the main tourism feeder market for Galicia and in relation with the eventual effects of climate change on destination preferences, it is worth noting the following distribution under the baseline scenario (figure 3), in order to contextualise that 5\% which translates into 6.5 million overnight stays in Galicia by Madrid residents.

And in the case of foreign tourism, in the minority in the north-west of Spain, it makes up $2.1 \%$ of the Spanish total. This fact implies the existence of a potential margin for other currently dominant destinations but concentrated in the south (Andalusia with $14.5 \%$, the Canary Islands with $16.4 \%$ or Valencia with $9.2 \%$ ) to move their preferences towards the north of Spain under a scenario we will evaluate herein. We believe this could be feasible in feeder markets from central and northern Europe, from where tourists mainly travel to spend their holidays (78.8\%), usually in the summer. 


\subsection{Method}

The methodology used to analyse changes in tourists' preferences towards coastal destinations under a climate change scenario is based on the economic valuation of stated preferences developed within the scope of environmental economics (Bateman et al., 2002). Economic valuation with stated preference techniques is applied to projects or measures which cause changes to social welfare, and its aim can be to quantify in economic terms the magnitude of such impacts or forecast modifications in the behaviour of individuals in certain simulated scenarios, to quantify such changes and subsequently convert them into economic dimensions. In this study, we will adopt this latter approach within the statedpreference techniques. The method used is a variation of the so-called contingent behaviour analysis. This method, as with the other techniques based on stated preferences, is based on a questionnaire in which a representative sample of the target population takes part. The questionnaire is defined following internationally-accepted protocols and it attempts to place the individual in a hypothetical future situation in which he will have to decide what his behaviour as a consumer would be or, implicitly, how his consumption behaviour would vary in quantity and type in this new situation.

In order to carry out the estimation, we drew up a questionnaire to be completed by Madrid residents who might have visited a Spanish coastal destination in the last year (June 2007June 2008). The questionnaire was divided up into four sections:

1. The first section aims to find out how many visits were made to the north-west of Spain during the reference period, in order to obtain specific data on each visit: the month in which it took place, the type of accommodation availed of, the approximate number of nights the visit lasted, the means of transport used to go to Galicia and the main reason for the trip. With sole regard to visits to the coast, the respondent was asked to point out the trips he thought were especially agreeable and satisfactory as well as those which did not live up to his expectations, and to specify the reasons why in both cases.

2. In the second section a similar process was undertaken, but relating to visits made to the Spanish coast (excluding Galicia), requesting specific data on each visit and for respondents to point out those that were particularly agreeable and disagreeable, as well as the reasons why.

3. Having completed the analysis of current tourist behaviour, the third section covers the importance of climate variables when deciding a holiday destination. Below we describe the hypothetical future scenario (in a context of climate change) which is accompanied by the corresponding contingent behaviour questions. It begins with a general line of questioning on how the respondent thinks tourist trips to Galicia and the number of overnight stays might change in the new context, if he personally would modify his trips to Galicia and the number of overnight stays on the coast. Finally, a question was posed which began by reminding the respondent of how many overnight stays he had made in the last year on the Galician coast and the rest of the Spanish coast, the aim of which was to quantify the behavioural change. He was then asked to estimate what trips he would make in the future bearing in mind the changes described. Respondents were also asked if they had a second home. Those who did were asked where, and if they would change the location of the second home in the new context. If they did not have a second home, they were asked where they would like to have one in such a future situation. 
4. The aim of the fourth and final section of the questionnaire was to find out the socioeconomic characteristics of respondents, such as their age, academic background, career situation, income, etc.

The text depicting the hypothetical future scenario described for the respondents to determine their contingent behaviour was as follows:

Access by road to the Spanish coast, including the north-west, has improved considerably, and in the coming years new high-speed rail links will make it possible to travel from Madrid to Galicia in approximately two hours.

Furthermore, experts consider that the following climate changes are already occurring:

- Precipitation will be concentrated in the autumn and will be lower throughout the rest of the year.

- Temperatures will undergo a general increase, especially in spring and summer. Furthermore, in summer and autumn the nights will be warmer.

- The sea temperature will rise.

- $\quad$ The sea level will rise.

With regard to Madrid, as well as the Mediterranean coast and the islands, being inland and further to the south, respectively, these changes will be more intensive than in Galicia".

This scenario was defined on the basis of prior information provided by biologists and other scientists. We chose to show qualitative information in order to facilitate the understanding of the information as well as the simplicity and brevity necessary for a telephone questionnaire.

With this methodology the individual has to choose between two alternatives: acquiring the product (tourism) with the usual characteristics, $z_{0}$ (in the current climate scenario); and acquiring the product with an additional attribute (the new climate scenario), at a specific cost for respondents (option $z_{1}$ ). We assume that the researcher does not know the true preferences of the respondents; therefore the social welfare function will be defined by the following expression:

$$
V\left(z_{j}\right)=v\left(z_{j}\right)+\varepsilon_{j}, \quad j=0,1
$$

where $\varepsilon$ is the error term or the part not observed by the researcher, and it is considered to be a identically distributed independent random variable with mean zero. Through the valuation exercise, the researcher offers the respondent the possibility of acquiring products at a price $A$. The researcher can only assume that the reply is a random variable with a probability function,

$$
\begin{gathered}
\operatorname{Pr}(\text { if } / A)=\operatorname{Pr}\left\{V\left(z_{1}\right)>V\left(z_{0}\right)\right\} \\
=\operatorname{Pr}\left\{v\left(z_{1}\right)+\varepsilon_{1}>v\left(z_{0}\right)+\varepsilon_{0}\right\} \\
=\operatorname{Pr}\left\{v\left(z_{1}\right)-v\left(z_{0}\right)>\left(\varepsilon_{0}-\varepsilon_{1 i}\right)\right\} \\
=\operatorname{Pr}\left\{\Delta v>\left(\varepsilon_{0}-\varepsilon_{1 i}\right)\right\}
\end{gathered}
$$


Where $\operatorname{Pr}(i f / A)$ is the probability the respondent will accept the exchange at the proposed price and $P($ not $/ A)=1-P(i f / A) . \quad \eta=\varepsilon_{0}-\varepsilon_{1}$ and $F \eta$ will be its cumulative distribution function. If this distribution function is specified as logistic, we are facing a logit model,

$$
\operatorname{Pr}(\text { if } / A)=F_{\eta}(\Delta v)=\frac{1}{1+e^{-\Delta v}}
$$

whereby, if we also assume that the utility function is linear, the utility differential can be expressed as follows:

$$
\Delta v=\alpha+\gamma A, \quad \alpha=\alpha_{0}-\alpha
$$

where $\gamma$ is the coefficient associated with the price attribute. By substituting in the probability expression, the following is obtained:

$$
\operatorname{Pr}(\text { if } / A)=F_{\eta}(\Delta v)=\frac{1}{1+e^{-\left(\alpha+\gamma A_{i}\right)}}
$$

the resulting regression equation will be

$$
\ln \left(\frac{\operatorname{Pr}(\text { if } / A)}{1-\operatorname{Pr}(\text { if } / A)}\right)=\alpha+\gamma A
$$

On the other hand, if the individual is prepared to pay the quantity $A$, then the willingness to pay $(D)$ is greater than $A$. Formally,

$$
F_{\eta}(\Delta v)=\operatorname{Pr}(\Delta v>\eta)=\operatorname{Pr}(D>A)=1-G_{D}(A)
$$

where $G_{D}(A)$ is the cumulative distribution of the individual's willingness to pay. That is, the probability that the individual's social welfare will be greater if he accepts the exchange is directly related to the probability that his true willingness to pay is higher than the price.

\subsection{Results}

The questionnaires designed in order to analyse tourist preferences and their changes under a climate change scenario were carried out by professional pollsters in the month of July 2008 at Madrid City Council. The questionnaires were administered over the telephone and the numbers were dialled at random with quotas in accordance with age. 1495 people were contacted, of which 745 agreed to complete the questionnaire, which is a response rate of $49.8 \%$, usual in this type of study. Of the 745 people who agreed to take part, $131(17.6 \%)$ had visited Galicia in the last year (17.6\%). (Therefore, 614 or $82.4 \%$ had not visited Galicia). This percentage exceeds to some degree the data provided by Familitur on the source Madrid and destination Galicia put at $5.03 \%$ on the baseline scenario. 73 people declared themselves to be visitors to the Galician coast (55.7\% of those who had visited Galicia); 38 were inland visitors (29\%) and 20 had visited both the coast and an inland region (15.3\%). Therefore, 93 people ( $71 \%$ of those who had visited Galicia) had visited the Galician coast. From the initial sample $396(53.2 \%)$ had visited the Spanish coast (excluding the Galician coast) during the last year (349 or $43.8 \%$ had not visited it). Considering the initial sample, we can see that 349 people had not visited either the Galician or the Spanish coast $(46.84 \%)$; 
59 had visited both (8\%); 34 only the Galician coast $(4.5 \%)$ and 337 only the Spanish coast $(45.23 \%)$.

\begin{tabular}{|c|c|c|c|c|}
\hline & \multicolumn{2}{|c|}{ First trips } & \multicolumn{2}{c|}{ Second trips } \\
\hline & Frequency & Percentage & Frequency & Percentage \\
\hline Work & 8 & 7.0 & & \\
\hline $\begin{array}{c}\text { To visit family and/or } \\
\text { friends }\end{array}$ & 18 & 15.7 & 4 & 33.3 \\
\hline To enjoy the beaches & 13 & 11.3 & 1 & 8.3 \\
\hline To go walking or trekking & 6 & 5.2 & 0 & 0 \\
\hline Mountain sports & 1 & 0.9 & 0 & 0 \\
\hline $\begin{array}{c}\text { To visit historical } \\
\text { monuments }\end{array}$ & 1 & 0.9 & 1 & 8.3 \\
\hline $\begin{array}{c}\text { To visit charming towns } \\
\text { and villages }\end{array}$ & 10 & 8.7 & 1 & 8.3 \\
\hline To enjoy the gastronomy & 10 & 8.7 & 1 & 8.3 \\
\hline Others & 48 & 41.7 & 1 & 33.3 \\
\hline Total & 115 & 100.0 & 12 & 100.0 \\
\hline
\end{tabular}

Table 7. Reason for the trip (to the Galician coast).

The sample size finally used for the statistical analysis is obtained after applying a sample filter, and the useful sample is constituted by integrating the visitors to the Spanish or Galician coast in the last year. With the selection, the final sample is made up of 430 people (who visited either the Galician or Spanish coast). We excluded those who visited inland Galicia and did not visit the coast (16 people are not current users of the coast). The end distribution of the sample according to their use of the coast remains as follows: of the 430 visits to the Spanish coast (excluding the Galician coast), $78.37 \%$ only visited the Spanish coast, $13.72 \%$ visited the Spanish as well as the Galician coast, and $7.9 \%$ visited the Galician coast but not the Spanish coast.

Table 7 shows the main reasons for the trips made to Galicia in the last year. $41 \%$ did not choose any of the reasons specified and gave a combination of reasons which were equally important for their decisions. It can be seen that visits to family and friends are the principle cause for those who chose some main reason (15.7\% of the sample), the second (11.3\%) being to enjoy the beaches and the third $(8.7 \%)$ for its gastronomy.

When the reasons for especially satisfactory trip or trips are analysed, the main reason most of the respondents underlined (table 8 ) was the green landscape and woodland $(46.51 \%)$, followed by the agreeable climate $(11.63 \%)$. Secondary reasons included firstly the gastronomy $(39 \%)$, followed by the green landscape and woodland $(19.4 \%)$ and the climate $(6 \%)$. Of those who state a third reason, $32 \%$ specify the amicability of the people and $13 \%$ the climate.

As we can see, the climate features in the three most-mentioned reasons, be it in first, second or third place. The people who mentioned more than one reason were asked what they considered the most important to be, and in the distribution of responses $40 \%$ replied the green landscape and woodland, $16 \%$ the gastronomy, $15 \%$ the amicability of the people, $12 \%$ the climate and $10 \%$ the quiet and non-overcrowding. In the case of trips to Galicia, only five people mentioned a trip that did not meet their expectations, four for reasons relating to the poor quality of the accommodation and one for the unpleasantness of the people. 
In relation with trips to the Spanish coast, when the respondents were asked to specify the main reason for their trip (table 9), and in the same way as in the case of trips to Galicia, a significant number pointed to a combination of factors all of which were equally important. Of the individuals who stated a specific reason, beach-based recreation was the most frequent reason (with $28 \%$ of first trips and $20 \%$ of second ones), followed by visits to family or friends (14\% and $18 \%$, respectively).

\begin{tabular}{|c|c|c|c|c|c|c|}
\hline & \multicolumn{2}{|c|}{ Reason 1 } & \multicolumn{2}{c|}{ Reason 2 } & \multicolumn{2}{c|}{ Reason 3 } \\
\hline & Frequency & $\%$ & Frequency & $\%$ & Frequency & $\%$ \\
\hline $\begin{array}{c}\text { Green landscape } \\
\text { and woodland }\end{array}$ & 40 & 46.51 & 13 & 19.40 & 3 & 6.38 \\
\hline Gastronomy & 7 & 8.14 & 26 & 38.81 & 5 & 10.64 \\
\hline $\begin{array}{c}\text { Amicability of } \\
\text { the people }\end{array}$ & 7 & 8.14 & 7 & 10.45 & 15 & 31.91 \\
\hline Pleasant climate & 10 & 11.63 & 4 & 5.97 & 6 & 12.77 \\
\hline $\begin{array}{c}\text { Cultural and } \\
\text { historical } \\
\text { heritage }\end{array}$ & 2 & 2.33 & 3 & 4.48 & 2 & 4.26 \\
\hline $\begin{array}{c}\text { Quality and } \\
\text { proximity of the } \\
\text { beaches }\end{array}$ & 2 & 2.33 & 3 & 4.48 & 1 & 2.13 \\
\hline $\begin{array}{c}\text { Quiet and non- } \\
\text { overcrowding }\end{array}$ & 4 & 4.65 & 3 & 4.48 & 4 & 8.51 \\
\hline Other & 14 & 16.28 & 8 & 11.94 & 11 & 23.40 \\
\hline Total & 86 & 100.00 & 67 & 100.00 & 47 & 100.00 \\
\hline
\end{tabular}

Table 8. Reasons why the trip (to the Galician coastline) was especially pleasant or satisfactory.

\begin{tabular}{|c|c|c|c|c|}
\hline & \multicolumn{2}{|c|}{ First trips } & \multicolumn{2}{c|}{ Second trips } \\
\hline Work & Frequency & Percentage & Frequency & Percentage \\
\hline $\begin{array}{c}\text { To visit family and/or } \\
\text { friends }\end{array}$ & 14 & 3.5 & 7 & 6.7 \\
\hline To enjoy the beaches & 56 & 14.1 & 19 & 18.3 \\
\hline $\begin{array}{c}\text { To go walking or } \\
\text { trekking }\end{array}$ & 25 & 28.3 & 21 & 20.2 \\
\hline Mountain sports & 112 & 6.3 & 8 & 7.7 \\
\hline $\begin{array}{c}\text { To visit historical } \\
\text { monuments }\end{array}$ & 3 & 0.8 & 1 & 1.0 \\
\hline $\begin{array}{c}\text { To visit charming towns } \\
\text { and villages }\end{array}$ & 11 & 2.8 & 4 & 0 \\
\hline To enjoy the gastronomy & 15 & 3.8 & 1 & 3.8 \\
\hline Others & 159 & 40.2 & 43 & 41.3 \\
\hline Total & 396 & 100.0 & 104 & 100.0 \\
\hline
\end{tabular}

Table 9. Reason for the trip (to the Spanish coast). 
In the total sample, 306 people were of the opinion that their trips were especially satisfactory, 4 that none was satisfactory and 86 mentioned an especially pleasant trip. In total, 392 had at least one especially satisfactory trip to the Spanish coast. Table 10 shows the main reasons for their opinions. Of the reasons they mention in first place, landscape is the most frequent $(32.4 \%$ of the sample), followed by climate $(21 \%)$. Of those mentioned in second place, the most important are gastronomy and climate ( $25 \%$ and $12 \%$, respectively), and those who give a third reason point to the amicability of the people $(21 \%)$ and the climate $(14 \%)$. As we can see, the climate, in this case, is also quoted as one of the first three reasons relating to the satisfactory nature of the trip.

\begin{tabular}{|c|c|c|c|c|c|c|}
\hline & \multicolumn{2}{|c|}{ Reason 1 } & \multicolumn{2}{c|}{ Reason 2 } & \multicolumn{2}{c|}{ Reason 3 } \\
\hline & Frequency & \% & Frequency & \% & Frequency & $\%$ \\
\hline & 127 & 32.4 & 26 & 11.02 & 14 & 9.59 \\
\hline Gastronomy & 15 & 3.8 & 60 & 25.42 & 13 & 8.90 \\
\hline $\begin{array}{c}\text { Amicability of } \\
\text { the people }\end{array}$ & 36 & 9.2 & 37 & 15.68 & 31 & 21.23 \\
\hline Pleasant climate & 83 & 21.2 & 28 & 11.86 & 21 & 14.38 \\
\hline $\begin{array}{c}\text { Historical and } \\
\text { cultural heritage }\end{array}$ & 4 & 1.0 & 9 & 3.81 & 5 & 3.42 \\
\hline $\begin{array}{c}\text { Quality and } \\
\text { proximity of the } \\
\text { beaches }\end{array}$ & 25 & 6.4 & 26 & 11.02 & 17 & 11.64 \\
\hline $\begin{array}{c}\text { Quiet and non- } \\
\text { overcrowding }\end{array}$ & 37 & 9.4 & 22 & 9.32 & 16 & 10.96 \\
\hline Others & 65 & 16.6 & 28 & 11.86 & 29 & 19.86 \\
\hline Total & 392 & 100.0 & 236 & 100.00 & 146 & 100.00 \\
\hline
\end{tabular}

Table 10. Reasons why the trip (to the Spanish coast) was especially pleasant or satisfactory.

\begin{tabular}{|c|c|c|c|c|}
\hline & \multicolumn{2}{|c|}{ Positively } & \multicolumn{2}{c|}{ Negatively } \\
\hline & Frequency & Percentage & Frequency & Percentage \\
\hline Mild temperatures & 22 & $61.1 \%$ & 16 & $13.8 \%$ \\
\hline Rainfall & 7 & $19.4 \%$ & 81 & $69.8 \%$ \\
\hline Wind & 1 & $2.8 \%$ & 2 & $1.7 \%$ \\
\hline Cloud/fog & 0 & $0 \%$ & 3 & $2.6 \%$ \\
\hline Colder sea temperature & 4 & $11.1 \%$ & 12 & $10.3 \%$ \\
\hline Waves & 0 & 0 & 0 & 0 \\
\hline Snow & 0 & 0 & 0 & 0 \\
\hline Others & 2 & $5.6 \%$ & 2 & $1.7 \%$ \\
\hline Total & 36 & 100.0 & 116 & 100.0 \\
\hline
\end{tabular}

Table 11. Influence of climate on your decision to visit Galicia.

In relation with the contingent behavior analysis, when questioned whether the climate influenced their decision to visit Galicia or not, 35\% of the respondents (152 individuals) answered that it did, 60\% (258) that it did not and 4.7\% (20) did not reply. Of those who 
answered in the affirmative, $23.7 \%$ (36 replies) indicated that the climate influenced them positively, and $76.3 \%$ (116) that it influenced them negatively. The climate variable that has the most positive influence is the mild temperature, mentioned by $61 \%$ of respondents. The most important negative climate variable is the risk of rain (table 11).

Once the expected changes for the years to come have been described, both with regard to improvements in infrastructures as well climate (in Galicia and Madrid), the respondents were asked if they thought that under this scenario tourist visits to Galicia would increase or decrease. $67 \%$ of those who visited the coast ( 287 people) considered that the affluence of tourists to Galicia would increase; $18 \%$ (79 people) thought that it would not change; and only $3 \%$ thought that visits to Galicia would decrease in the new context; $12 \%$ pointed out that they could not venture to make such a prediction.

Under the new scenario and when asked whether Galicia would be more attractive to them as a destination, they stated the following. For approximately 50\%, Galicia's attractiveness as a destination would increase in the new situation; $36 \%$ would not modify their current opinion and, finally, 5\% would consider Galicia as a less attractive destination. $9 \%$ did not venture an opinion on this point.

When asked whether their overnight stays on the Galician coast would increase or decrease, the replies were distributed in the following manner: $48 \%$ stated that under the new scenario they would make more overnight stays on the Galician coast; approximately 35\% said that they would maintain their current number of stays; and only $4 \%$ said that they would make less overnight stays. $13 \%$ stated no opinion on this point.

The respondents were then asked to quantify changes in overnight stays. We will begin by analysing the variation in total overnight stays on the Spanish coast (including the Galician coast) to subsequently describe how future overnight stays are divided up between the Galician coast and the remaining Spanish coast.

We start off from the information obtained from the sample itself which indicates that 430 of the respondents visited the Spanish coast (including the Galician coast) and made 5339 overnight stays. Of the 428 respondents who answered the question on quantifying the changes, $76(17.76 \%)$ would reduce their overnight stays on the coast under the new scenario, 157 (36.68\%) would maintain the same number and 195 (or $45.46 \%$ ) would increase their overnight stays.

Having presented the variations in overnight stays, it is deduced that they would increase by 2384 and drop by 652, with a final positive result in the form of a net increase of 1732 overnight stays (per year). The number of overnight stays would rise to 7071 (as opposed to the current 5339), with an increase in percentage terms of 32.44.

However, these global figures hide a very different situation between the changes observed in demand if we consider the Spanish coast and focus on the Galician coast. Beginning with the Spanish coast, currently 337 of the people polled visited the Spanish coast (excluding Galicia) and made 4421 overnight stays in the last year. In this case, of the 428 people who answered the question on changes, $161(37.61 \%)$ would maintain their overnight stays, 153 (35.74\%) would reduce them and $82(19.16 \%)$ would increase them.

When presenting the variation in overnight stays, it can be observed that they would increase by 725 and drop by 1194, with a negative net result of -469 overnight stays in a year. The prediction, therefore, would be that the number of overnight stays per year in the sample on the Spanish coast, excluding the Galician coast, would drop from 4421 to 3952, with an approximate decrease in percentage terms of 11 . 
Analysing the variations in visits to the Galician coast, the data from the sample shows that in the last year, 93 people visited the Galician coast and made 918 overnight stays. Of the 428 people who answered the question on the quantification of changes, $22(5.14 \%)$ would reduce their overnight stays on the Galician coast in the new situation, 139 (32.48\%) would maintain them and 267 (62.38\%) would increase the number of overnight stays they make.

Overnight stays would increase by 2226 and fall by 207, with a positive final result in the form of a net increase of 2019 overnight stays (per year). The number of overnight stays would rise to 2937, therefore (as opposed to 918 at present), with an approximate increase of $220 \%$.

We will now describe the changes in preferences associated with a second home in a future climate change context. In the final sample, 146 people (34\%) currently have a second home, a figure which closely resembles that obtained in the baseline scenario for Madrid $(36.9 \%$ according to Familitur). Of these, 1.9\% (8 individuals) has a second home in Galicia; 31.6\% (136 people) on the Spanish coast and 2 people have a second home in another country. Only 17 people $(11.6 \%)$ would change their residence under the new scenario, which indicates more rigid tourist behavior associated with second homes. The places to which they would change are presented in table 12, with a greater preference for Andalusia $(23.53 \%)$, followed by Galicia and the Autonomous Community of Valencia (both with $17.65 \%)$.

Of the 284 individuals from the sample who do not currently have a second residence (66\% of visitors to the coast), 33\% would not know where to buy a second home if they had the opportunity to do so (79 people), 39\% (111 people) would prefer to buy it on the Mediterranean, $22.5 \%$ in northern Spain (64 people), $4 \%$ in inland Spain (12 people) and 4 people $(1.4 \%)$ chose other places (other countries).

\begin{tabular}{|l|l|l|}
\hline & Frequency & Percentage \\
\hline Asturias & 1 & 5.88 \\
\hline Andalusia & 4 & 23.53 \\
\hline Galicia & 3 & 17.65 \\
\hline Avila & 2 & 11.76 \\
\hline A.C. of Valencia & 3 & 17.65 \\
\hline North & 1 & 5.88 \\
\hline The Coast & 1 & 5.88 \\
\hline Zamora & 1 & 5.88 \\
\hline Ibiza & 1 & 5.88 \\
\hline Total & 17 & 100.00 \\
\hline
\end{tabular}

Table 12. Place to which they would change their second home under the new climate scenario.

Lastly, in relation with the characteristics of the sample, 405 people were in their habitual residence, $94.2 \%$ of the sample. 18 was the average number of years that they had been living in that residence. The average age of those polled was 45 (with a minimum of 25 and a maximum of 75), which is representative of the target population. $63 \%$ of the sample was 
women. This percentage is higher than that of the population because in this case quotas per sex were not applied given that the interest lay in the questionnaire being answered by a family member who made the decision on holiday destinations. The average number of family members was 3.13 (median 4). In $65 \%$ of the homes that participated in the sample there were no under-19s, in $17 \%$ there was one and in $15 \%$ there were two. There were more than two in the remaining $10 \%$. In $79 \%$ of the homes there were no over- 65 s, there was one in $14 \%$ and two in $6 \%$. Only in $0.9 \%$ were there more than two over-65s. Only $4.2 \%$ stated they had a family member born in Galicia. $96 \%$ had heating in their homes $(62 \%$ had natural gas) and $61 \%$ had air conditioning. $86 \%$ of respondents had a car and, of these, $98 \%$ had heating-ventilation-air conditioning. 138 personas (32.2\% of respondents) had studied to high-school level and 227 people (53\%) affirmed that they were the main breadwinner in the family.

\section{Conclusions}

In this chapter we have analysed the effects of climate change on the anchovy fishery and tourism flows in the north-west of Spain. To do so, we have taken into consideration possible future scenarios involving sea surface temperature increases and possible coastal and climate modifications in the region.

In relation with the effects on the anchovy fishery, we have used a bio-economic model applied to this fishery, which has allowed us to gauge the environmental effects as well as natural and economic factors. Climate change was gauged on the basis of sea surface temperature. The results obtained indicate a reduction both in future fish biomass as well as catch levels. This would be so both if the trend forecast for rises in sea temperatures follows past trends (foreseeable according to oceanographers; Roson, 2008) as well as if an even greater warming occurred as a result of global warming.

Given the poor situation of anchovy biomass as a consequence of low recruitment in recent years, the European Commission implemented a moratorium in the fishery for the period 2005-2009, both inclusive. Consequently, we assumed as a baseline scenario that which corresponded to the last year of fishing activity before the moratorium, that is, 2004. As a summery, table 13 shows the net profits that correspond to the baseline scenario and those that would be obtained on the 2040 time horizon, and for both scenarios with regard to sea surface temperature oscillation (this horizon corresponds to the intermediate period used in the EC Peseta Report).

\begin{tabular}{|c|c|}
\hline Scenarios & Value (x10 Euros $^{\text {) }}$ \\
\hline Baseline scenario & 23,721 \\
\hline Climate scenario (1) & 14,947 \\
\hline Climate scenario (2) & 14,795 \\
\hline Variation rate for scenario (1) & $-1.274 \%$ \\
\hline Variation rate for scenario (2) & $-1.303 \%$ \\
\hline
\end{tabular}

Table 13. Summary of estimated losses in the anchovy fishery (NW zone).

Therefore, the effects of sea surface temperature increases, assuming that the rest of the parameters remain constant, generate a reduction in net profits of $1.27 \%$ and $1.30 \%$, respectively, if the sea temperature increases according to the trend over recent years, or if it increases at a greater rate than that observed to date. 
With respect to tourist activity, a questionnaire was drawn up to reveal the tourist behavior, present and future, of the main tourism market in north-western Spain (Madrid). The questionnaire was applied over the telephone and a useful sample (of visitors to the Spanish coast over the previous year) of 430 people was obtained. Of these, $78 \%$ had visited the Spanish coast in that period, $8 \%$ had visited the Galician coast and $14 \%$ had visited both. Of those who had visited Galicia, more than half had made their trips in the summer, at an average of 10 overnight stays per visitor per year. Visitors to Galicia stayed mainly in hotels $(42 \%)$ and rented apartments or flats $(18 \%)$. They had travelled mainly in their own car $(75 \%)$ and the main reason for the trip was to holiday, with a mixture of aims (beach, gastronomy, etc.). In general, they stated they were very satisfied with their trips, mainly motivated by the landscape, climate being among the three main reasons mentioned as agreeable factors.

Visitors to the Spanish coast spent an average of 11 nights per year and also made their trips mainly in the summer (62\%). 33\% stayed in hotels, followed by $25 \%$ who stayed in rented apartments or flats. Once again, their own cars were the main means of travel from Madrid to the coast $(72 \%$ used their own car to travel) and the reason for the trip was also to holiday, in general. The respondents also affirmed that they were highly satisfied with their trips, the main reasons for this being the landscape and the climate, although $10 \%$ stated that one of the trips did not live up to their expectations, the reasons being the quality of the accommodation, the climate or noise and congestion.

It can be observed that the climate appears as a key reason to satisfaction or dissatisfaction with trips throughout the analysis. When asked about the extent to which the climate influences their decisions to visit the north-west, 35\% admit that this variable did indeed influence their decisions. For $76 \%$ of those who admitted to being influenced by the climate, it was negative or off-putting, mainly due to the risk of rain, low temperatures and the low temperature of the sea.

With regard to the future climate change scenario, both in the north-west as well as the source (Madrid), and in the rest of the Spanish coast, most of the respondents $(67 \%)$ were of the opinion that the tourism flow to the north-west would increase in the new context. For $50 \%$, the attractiveness of the region would increase, and $48 \%$ affirm that they would increase their number of overnight stays in the region. The quantification of this increase in overnight stays indicates that only $5.4 \%$ would reduce their current number of stays, $32 \%$ would maintain them and $62 \%$ would increase them. The net increase would be +2.019 overnight stays (per year), which would involve a $220 \%$ increase with regard to the current number of stays in the sample analysed. This increase would occur to the detriment of trips to other areas of the Spanish coast (not the north-west). Thus, 38\% of visitors to other parts of the Spanish coast would maintain the number of overnight stays in those destinations, $19 \%$ would increase them and $36 \%$ would reduce them. The total number of overnight stays would undergo a net reduction of approximately $11 \%$ with respect to the situation as it stands at present.

If we assume that tourist demand for the north-west of Spain originating in the rest of Spain adapts to the preferences of the source market of Madrid for the climate change scenario proposed, the consequences could be simulated (table 14) in two alternative scenarios (minimum with a $50 \%$ increase; and $100 \%$ or duplication maximum ). Therefore, we would have the following differential impact on the GDP and in respect of the baseline scenario described in various paragraphs above: 


\begin{tabular}{|c|c|}
\hline Scenarios & Value (x106 Euros) \\
\hline Baseline scenario & 907.00 \\
\hline Minimum scenario (1) & $1,360.00$ \\
\hline Maximum scenario (2) & $1,814.00$ \\
\hline Effect on the GDP (1) & $+1 \%$ \\
\hline Effect on the GDP (2) & $+2 \%$ \\
\hline
\end{tabular}

Table 14. Summary of estimated gains in tourism (NW zone).

To sum up, and considering only these two economic activities, the effect of climate change on the north-west of Spain would generate estimated gains of approximately 1300 million euros on account of the significant importance of the tourist sector in the region and the foreseeably greater number of tourists who would visit it from other regions which would be harmed by the temperature increase forecast (the South and East of Spain).

In summary, in this chapter we assess the possible economic effects of global warming on some of the main economic activities in north-western Spain: the anchovy fishery and tourist activity. With regard to fishing activity, the results showed that if the sea surface temperature trend in the Ibero-Atlantic fishing grounds continues to show warming, both the biomass and the expected profits will drop. With relation to tourist activity, the results showed that the demand for trips and overnight stays would increase in the new climate scenario and the north-west, which would become a more attractive destination for current and potential visitors. The increase in demand would come about as a result of a drop in demand for current destinations as well as a net increase in the number of tourist trips regarding the market analysed.

\section{References}

ACIA (2004): Artic climate impacts assessment: Overview Report. Cambridge University Press, Cambridge.

Arnason, R. (2005): Climate change and fisheries: assessing the economic impact in Iceland and Greenland. Workshop on economic effects of climate change on fisheries, Bergen.

Arnason, R. (2006): Global warming, small pelagic fisheries and risk. En R. Hannesson, M. Barange, S. Herrick (Eds): Climate change and the economics of the world's fisheries. Edward Elgar Publishing.

Bateman, I. J.; Carson, R. T.; Day, B.; Hanemann, M.; Hanley, N.; Hett, T.; Jones-Le, M.; Loomes, G.; Mourato, S.; Ozdemiroglu, E.; Pearce, D. W.; Sugden, R.; Swanson, J. (2002), Economic Valuation with Stated Preference Techniques: A Manual. Edwar Elgar, Cheltenham, UK.

Bigano, A.; Hamilton, J. M.; Lau, M.; Tol, R. S. J. e Zhou, Y. (2004). A Global Database of Domestic and International Tourist Numbers at National and Subnational Level. Fondazione Eni R. Mattei. Working Papers, n 305, Milano, Italy.

Bigano, A.; Hamilton, J. M.; Maddison, D. J. e Tol, R. S. J. (2006). Predicting tourism flows under climate change. Climatic Change, 79, 175-180.

Briones, R., Garces, L., Ahmed, M. (2006): Climate change and small pelagic in developing Asia: the economic impact on fish producers and consumers. En R. Hannesson, M. Barange, S. Herrick (Eds): Climate change and the economics of the world's fisheries. Edward Elgar Publishing. 
Coenen \& Van Eekeren. (2003). A study of demand for domestic tourism by Swedish households using a two-staged budgeting model. Scandinavian Journal of Hospitality and Tourism, 3(2), 114-133.

EEA (2007). Climate change: the cost of inaction and the cost of adaptation. European Environmental Agency Technical Report 13/2007.

Eide, A. (2005): Economic impactas of global warming. The case of the Barents Sea fisheries. Workshop on economic effects of climate change on fisheries, Bergen.

European Commission (2006): Economic Performance of important segments fleets. Brussels.

European Commission (2007). Limiting Global Climate Change to 2 degrees Celsius. The way ahead for 2020 and beyond. Communication from the Commission to the Council, the European Parliament, the European Economic and Social Committee and the Committee of the Regions.

Evans et al. (2000). Planning for leisure and tourism. Report prepared to DETR Planning Research Programme, DETR, London.

Gallagher, Ch. (2005): Variable abundance and fishery movements in New Zeland squid fisheries: Preliminary findings from global and regional investigations. Workshop on economic effects of climate change on fisheries, Bergen.

Garza-Gil, M.D., Torralba-Cano, J., Varela-Lafuente, M. (2011): Evaluating the economic effects of climate change on the European sardine fishery. Regional Environmental Change 11, 87-95.

Gómez Martín, M. B. (2005). Weather, Climate and Tourism: a geographical perspective. Annals of Tourism Research, 32(3), 571-591.

Hamilton, J. M.; Maddison, D. J. e Tol, R. S. J. (2005a). Climate Change and International tourism: a simulation study. Global Environmental Change, 15, 253-266.

Hamilton, J. M.; Maddison, D. J. e Tol, R. S. J. (2005b). The effects of Climate Change on international tourism. Climate Research, 29, 255-268.

Hannesson, R. (2006): Sharing the herring: fish migrations, strategic advantage and climate change. En R. Hannesson, M. Barange, S. Herrick (Eds): Climate change and the economics of the world's fisheries. Edward Elgar Publishing.

Herrick, S., Hill, K., Reiss, C. (2006): An optimal harvest policy for the recently renewed United States Pacific sardine fishery. En R. Hannesson, M. Barange, S. Herrick (Eds): Climate change and the economics of the world's fisheries. Edward Elgar Publishing.

Ibermix (2007). Identification and segmentation of mixed-species fisheries operating in the Atlantic Iberian Peninsula waters. EC Project, FISH/2004/03-33.

ICES (2008). Report of the Working Group on the Assessment of Mackerel, Horse Mackerel, Sardine and Anchovy. Headquarters, ICES CM 2007/ ACFM; 31.

IET (2007). Familitur-Comunidad de Madrid, Año 2006. www.iet.tourspain.es

IET (2007). Movimientos turísticos de los españoles (Familitur) 2006. www.iet.tourspain.es

IET (2007). Movimientos turísticos en fronteras (Frontur) 2006. www.iet.tourspain.es

IGE (2010): A economía galega a través do Marco Input-Output de Galicia 2005. Instituto Gallego de Estatística, Santiago de Compostela.

IPCC (2001): Climate Change 2001: impacts, adaptation, and vulnerability. Contribution of Working Group II to the third assessment report of the Intergovernmental Panel on Climate Change. New York, USA: Cambridge University Press. 
IPCC (2007): 4th Report of International Panel for Climate Change. www.ipcc.ch.

Kamien, M. \& Schwartz, N. (1991). Dynamic Optimization. The Calculus of Variations and Optimal Control in Economics and Management. New York: North-Holland Ed.

Levitus, S., Antonov, J.I., Boyer, T.P., Stephens, C. (2000): Warming of the world ocean. Sciences, 287, 2225-2229.

Limb, M. \& Spellman, G. (2001). Evaluating domestic tourists' attitudes to British weather. A qualitative approach. Proceedings of the First International Workshop on climate, tourism and recreation. Halkidiki, Greece.

Lise, W. \& Tol, R. S. J. (2002). Impact of Climate Change on Tourist Demand. Climatic Change, 55, 429-449.

Maddison, D. (2001). In search of warmer climates?. The impact of Climate Change on Flows of British Tourists. Climatic Change, 49, 103-208.

MAPA (2008). La Agricultura, la Pesca y la Alimentación en España, Informe Anual. Ministerio de Agricultura, Pesca y Alimentación, Madrid.

McGowan, J.A., Cayan, D.R., Dorman, L.M. (1998): Climate-ocean variability and ecosystem response in North Pacific. Science, 281, 201-217.

Ministerio de Medio Ambiente (2005). Principales conclusiones de la evaluación preliminar de los impactos en España por efecto del cambio climático. Oficina Española de Cambio Climático (OECC), Ministerio de Medio Ambiente.

Ministerio de Medio Ambiente (2006): Plan Nacional de Adaptación al Cambio Climático, Madrid.

Naranjo, L. \& Pérez, V. (2006). A variabilidade natural do clima en Galicia. Fundación CaixaGalicia e Xunta de Galicia.

Perry, A. (2001). More heat and drought.Can Mediterranean tourism survive and prosper? In A., Matzarakis and C.R. de Freitas, eds., Procedings of the First International Workshop on Climate, Tourism and Recreation, International Society of Biometereology, Comission on Climate Tourism and Recreation, pp. 35-40.

Röckmann, C. (2005): Rebuilding the Eastern Baltic cod stock under environmental change. Workshop on economic effects of climate change on fisheries, Bergen.

Rosón, G. (2008): Índices climáticos y su impacto en la hidrografía y dinámica marina, Workshop Evidencias del cambio climático en Galicia, Santiago de Compostela.

Santos, F. D. \& Miranda, P. (2006). Alteraçoes climáticas em Portugal: cenarios, impactos e medidas de adaptaçao. Gradiva, Lisboa.

Scott, D.; McBoyle, G. \& Schwarzentruber, M. (2004). Climate Change and the distribution of climatic resources for tourism in North America. Climate Research, 27, 105-117.

Scott, D.; Wall, G. \& McBoyle, G. (2005). The evolution of the climate change issue in the Tourism sector. En: Hall, C. M.; Higham, J. (Eds.). Tourism, recreation and climate change. Channelview, London.

Seddigi, H. R. \& Shearing, D. F. (1997). The demand for tourism in North East England with special reference to Northumbria: an empirical analysis. Tourism Management, 18(8), 499-511.

Sissener, E.H. \& Bjorndal, T. (2005): Climate change and the migratory pattern for Norwegian spring-spawning herring: implications for management. Marine Policy 29, 299-309.

Smith, K. (1990). Tourism and Climate Change. Land Use Policy, 40, 371-389. 
Smith, K. (1993). The influence of weather and climate on recreation and tourism. Weather, 48, 398-404.

Stenevik, E.K., Sundby, S. (2007): Impacts of climate change on commercial fish stocks in Norwegian waters. Marine Policy, 31, 19-31.

Viner. D. \& Agner, M. (1999). Climate Change and its impacts on tourism. Climatic Research Unit, University of East Anglia, Norwich, U.K.

VV.AA. (2007): El cambio climático en España. Estado de situación. Ministerio de la Presidencia, Madrid.

World Tourism Organization (2006). Overview of International and European Tourism: 2005 results and short term outlook. www.world-tourism.org.

Xunta de Galicia-Exceltur (2005). Galicia-Impacto del turismo sobre la economía y el empleo. Estudio Impactur. www.exceltur.org 


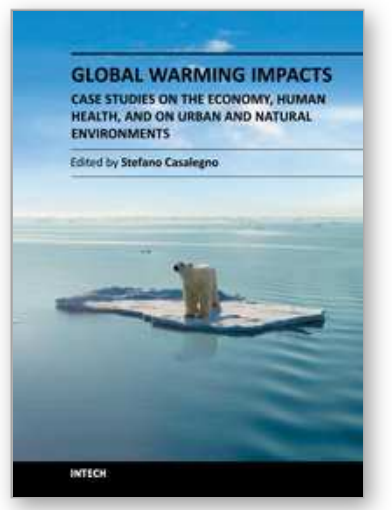

\author{
Global Warming Impacts - Case Studies on the Economy, Human \\ Health, and on Urban and Natural Environments \\ Edited by Dr. Stefano Casalegno
}

ISBN 978-953-307-785-7

Hard cover, 290 pages

Publisher InTech

Published online 03, October, 2011

Published in print edition October, 2011

This book addresses the theme of the impacts of global warming on different specific fields, ranging from the regional and global economy, to agriculture, human health, urban areas, land vegetation, marine areas and mangroves. Despite the volume of scientific work that has been undertaken in relation to each of each of these issues, the study of the impacts of global warming upon them is a relatively recent and unexplored topic. The chapters of this book offer a broad overview of potential applications of global warming science. As this science continues to evolve, confirm and reject study hypotheses, it is hoped that this book will stimulate further developments in relation to the impacts of changes in the global climate.

\title{
How to reference
}

In order to correctly reference this scholarly work, feel free to copy and paste the following:

M. Dolores Garza-Gil, M. Xosé Vázquez-Rodríguez, Albino Prada-Blanco and Manuel Varela-Lafuente (2011). Global Warming and Its Economic Effects on the Anchovy Fishery and Tourism Sector in North-Western Spain, Global Warming Impacts - Case Studies on the Economy, Human Health, and on Urban and Natural Environments, Dr. Stefano Casalegno (Ed.), ISBN: 978-953-307-785-7, InTech, Available from: http://www.intechopen.com/books/global-warming-impacts-case-studies-on-the-economy-human-health-andon-urban-and-natural-environments/global-warming-and-its-economic-effects-on-the-anchovy-fishery-andtourism-sector-in-north-western-s

\section{INTECH}

open science | open minds

\section{InTech Europe}

University Campus STeP Ri

Slavka Krautzeka 83/A

51000 Rijeka, Croatia

Phone: +385 (51) 770447

Fax: +385 (51) 686166

www.intechopen.com

\section{InTech China}

Unit 405, Office Block, Hotel Equatorial Shanghai

No.65, Yan An Road (West), Shanghai, 200040, China

中国上海市延安西路65号上海国际贵都大饭店办公楼 405 单元

Phone: +86-21-62489820

Fax: $+86-21-62489821$ 
(C) 2011 The Author(s). Licensee IntechOpen. This is an open access article distributed under the terms of the Creative Commons Attribution 3.0 License, which permits unrestricted use, distribution, and reproduction in any medium, provided the original work is properly cited. 